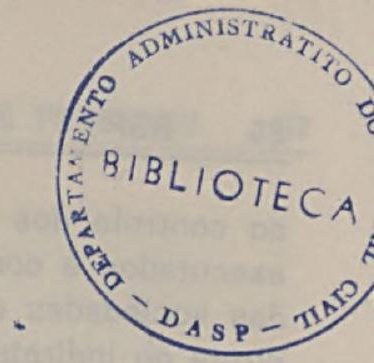

\title{
Aspectos do Controle Administrativo sobre os Territórios Federais
}

\author{
José Medeiros Vieira \\ Assessor Jurídico do Ministério do Interior
}

SUMARIO: INTRODUÇÃO. - TEMA I: "O controle dos fundos especiais distribuidos aos Territórios". - Os fundos especiais como instrumentos de correção dos desequilibrios regionais - Seu advento no sistema constitucional - Suas caracteristicas essenciais - Normas reguladoras - Os Territórios Federais em face da descentralização federativa - A pseudo-autonomia da administração territorial - Peculiaridades do exercício do controle da União sobre os Territórios Federals - Os sistemas de atividades auxiliares na legislação básica da Reforma Administrativa - As diferentes modalidades do controle administrativo - Singularidade do seu mecanismo - A tomada de contas anual como processo típico do controle a cargo das IGF - O certificado de auditoria - CONCLUSÃO. - TEMA II: "O controle das sociedades de economia mista constituídas nos Territórios". - Noção jurídica desse tipo de sociedade anônima - Posição do problema no direito brasileiro - Peculiaridades do controle da União sobre esses entes econômicos - Aplicabilidade do Dec.-lei n. ${ }^{\circ} 147 / 67$ - A representação da União - Prevalência dos dispositivos pertinentes do Dec.-lei n. ${ }^{\circ}$ 200/67 - CONCLUSÃO - CONCLUSÃO GERAL.

\section{INTRODU ÇÃ O}

O presente estudo focaliza, em correlação com os postulados básicos da Reforma Administrativa, dois temas concernentes à aplicação de normas legais a situações ocorrentes ao nível da administração territorial, e dizem respeito, um deles, 
ao controle dos recursos vinculados a programas e serviços executados à conta de fundos especiais, e outro, ao controle das sociedades de economia mista, de cujo capital participe, direta ou indiretamente, o Tesouro Nacional.

No primeiro caso, trata-se de saber se podem os recursos dos fundos especiais ser objeto de fiscalização e controle, em termos de auditoria única, pela Inspetoria-Geral de Finanças do Ministério do Interior, quando distribuídos aos Territórios Federais e por estes aplicados consoante as normas peculiares à sua execução.

No segundo, indaga-se, especificamente, se as sociedades de economia mista constituídas nos Territórios Federais, e de cujo capital estes participem, estão abrangidas pelas disposições do art. 39, e como tal sujeitas ao cumprimento das obrigações estatuídas nos arts. 43 e 45 , todos do Decreto-lei número $147 / 67$.

A colocação desses dois temas sob o mesmo enfoque, a despeito de revestirem aspectos distintos entre si, justifica-se pelo fato de suscitarem, ambos, questões atinentes ao exercício do controle da União sobre recursos oriundos do Tesouro Nacional, com especial referência à posição sui generis que os Territórios Federais ocupam entre as instituições do nosso direito público interno.

A par disso, há interesse em que resultem insuscetíveis de qualquer dúvida a natureza e a extensão desse controle, tendo em vista a disciplina própria que recebe no âmbito de sua legislação específica, em confronto com as disposições do Decreto-lei n. $200 / 67$.

As considerações que adiante se lêem, enfeixadas em dois capítulos distintos, pretendem oferecer resposta a cada uma dessas indagações, sob a perspectiva do ordenamento jurídico - constitucional brasileiro. 
TEMA PRIMEIRO

\section{O controle dos Fundos \\ Especiais distribuídos aos Territórios}

Em sentido amplo, os fundos especiais configuram uma técnica de intervenção do Estado no processo de desenvolvimento econômico. Por outras palavras, são formas de utilização dos instrumentos financeiros do Governo, com vistas à correção das desigualdades regionais em nível de vida e ritmo de crescimento, tendo por meta derradeira o desenvolvimento integrado da economia nacional.

Essa preocupação fundamental está patente, inclusive, na própria formulação da política tributária do Governo, através da criação de instrumentos de ação compatíveis com as características estruturais da economia brasileira, no atual estágio do seu desenvolvimento.

ALIOMAR BALEEIRO, em percuciente análise, divisa em tal política o objetivo de "homogeneizar economicamente o país, de sorte que as regiões mais desenvolvidas do Sul contribuísSem para a arrancada econômica das regiōes mais atrasadas do Nordeste, Norte e Centro-Oeste". 1

Esse mesmo aspecto é salientado na Exposição de Motivos n. 910, de 1965, mediante a qual o então Ministro da Fazenda submeteu ao Presidente da República o anteprojeto do Código Tributário Nacional, e em cujo item número seis se lê:

"Se a renda nacional tivesse formação mais uniforme em nosso País, a participação da receita segundo a arrecadação local seria insuficiente. Mas, ao contrário, a formação do produto nacional é fortemente concentrada na região Centro-Sul. 
Caso prevalecesse exclusivamente o critério de distribuição da receita tributária segundo a arrecadação local, os Estados de São Paulo e seus Municípios e o Estado da Guanabara ficariam excessivamente aquinhoados e muito mal assistido grande número de Estados e Municípios".

O fundo especial com caráter de receita vinculada teve seu advento, no campo político-constitucional, nos termos do art. 177 da Constituição de 1934, que estabeleceu a obrigatoriedade da aplicação, pela União Federal, segundo plano sistemático e permanente, de "quantia nunca inferior a quatro por cento de sua receita tributária" sem destinação especial, na defesa contra os efeitos das secas "nos Estados do Norte".

$\mathrm{Na}$ Constituição de 1946, essa quantia foi reduzida a três por cento da renda tributária, em relação ao "plano de defesa contra os efeitos da denominada seca no Nordeste" (art. 198), ao mesmo tempo em que, com esse caráter. se criava novo fundo, alicerçado em idêntico percentual sobre a renda tributária, especificamente destinado à execução do plano de valorização econômica da Amazônia (art. 199).

Daí por diante, novos fundos especiais foram instituídos por leis ordinárias, e até mesmo por via de decreto, generalizando-se de tal modo a sua prática que, segundo declarações da IGF do Ministério da Fazenda, "atualmente existem cerca de duzentos", dos quais trinta e três, apenas, movimentaram, no exercício de 1971, a título de débito e crédito, Cr\$ .......... 5.343.315.080,19 e CrS 5.248.185.627.05, respectivamente. ${ }^{2}$

Todavia, a expressão só veio a ser reconhecida e consagrada na Constituição de 1967, com a regra estatuída no seu art. 65, quanto à obrigatoriedade da inclusão, no orçamento anual, das "despesas e recursos relativos a todos os Poderes, órgãos e fundos, tanto da administração direta quanto da indireta", ressalvadas apenas as de entidades que não recebessem subvenções ou transferências orçamentárias. Esta regra, afinal, completava-se com a do parágrafo terceiro do mesmo artigo,

2 Apud Ministro MEM DE SA -. "O Apertelçoamento do Sistema de Controle de Contas" Conferência pronunciada por ocasião do encerramento do "Encontro Jurldico do MINTER", no dia 18 de agosto de 1972. 
que proibia fosse vinculada a arrecadação de quaisquer tributos a órgão, fundo ou despesa, excetuados os impostos únicos, as disposições constitucionais pertinentes e bem assim as das leis complementares.

A primeira vista, poderia afigurar-se que o mecanismo de formação dos fundos especiais, consistindo, basicamente, na transferência global de recursos, encontraria óbice incontornável no princípio vedatório da afetação da receita tributária, consubstanciado no preceito acima referido.

Mas, tanto não seria procedente essa conclusão, quanto a Constituição de 1969, embora seguindo a mesma orientação da anterior, no que concerne à matéria, houve por bem ressalvar, no parágrafo $2 .^{\circ}$ do seu art. 62 :

"A lei poderá, todavia, estabelecer que a arrecadação parcial ou total de certos tributos constitua receita do orçamento de capital, proibida sua aplicação no custeio de despesas correntes".

Tinha pertinência, pois, a observação de RUBEM DE OLIVEIRA LIMA, no sentido de que o preceito do art. 65 , $\S 3 .^{\circ}$, da Constituição de 1967, não atingia nem invalidava a existência dos fundos especiais, entendidos estes, que fossem, "como uma modalidade de despesa, tal como se fora uma dotação destinada a investimentos, com destaque especial e processo sui generis". 3

Assim concebidos, os fundos especiais resultam, em última análise, numa programação especial de despesa. As suas principais características residem:

a) na vinculação de uma receita ou dotação a determinado programa ou serviço;

b) na sua aplicação exclusiva nos objetivos declarados no diploma legal que o instituiu;

c) nas disponibilidades futuras dos saldos do exercício,

ou, noutros termos, no regime de gestão; e

d) na contabilidade própria.

3 RUBEM DE OLIVEIRA LIMA - Fundos Especiais, in Rev. do Trib. de Contas da União.
$n, 01,25$. 
As normas gerais atinentes a esses fundos estão consubstanciadas, em título especial, na Lei $n .^{\circ} 4.320$, de 17 de março de 1964, e distribuídas ao longo dos seguintes dispositivos:

"Art. 71 - Constitui fundo especial o produto de receitas especificadas que, por lei, se vinculam à realização de determinados objetivos ou serviços, facultada a adoção de normas peculiares de aplicação.

Art. 72 - A aplicação das receitas orçamentárias vinculadas a fundos especiais far-se-á através de dotações consignadas em Lei Orçamentária ou em créditos adicionais.

Art. 73 - Salvo determinação em contrário da lei que o instituiu, o saldo positivo do fundo especial apurado em balanço será transferido para o exercício seguinte, a crédito do mesmo fundo.

Art. 74 - A lei que instituir fundo especial poderá determinar normas peculiares de controle e prestação de contas, sem, de qualquer modo, elidir a competência do Tribunal de Contas ou órgão equivalente".

\section{III}

Respeitado o controle externo do Tribunal de Contas, os fundos especiais vêm sendo controlados, via de regra, nos termos das respectivas leis instituidoras, por órgãos integrantes da estrutura administrativa dos diferentes Ministérios Civis.

Compreende-se: à míngua de personalidade jurídica, esses fundos teriam, necessariamente, de ser administrados pela União Federal, que os institui, mas que, por sua vez, atribuil o exercício dessa gestão a entes personalizados de sua organização administrativa.

Daí a competência específica dos órgãos ministeriais pertinentes, no que tange ao controle dos fundos especiais distribuídos às pessoas jurídicas de direito público interno, nos diferentes níveis da descentralização federativa.

Com relação, em particular, ao exercício do controle desses fundos pelos órgãos federais responsáveis por sua gestão, 
cumpre distinguir, sob o aspecto de aplicação dos respectivos recursos, entre Estados e Municípios, de uma parte, e Territórios Federais, de outra, porquanto uns e outros têm colocação distinta nos quadros institucionais do nosso ordenamento constitucional.

O Estado Moderno, segundo a lição de ROGER BONNARD, é a instituição personificada numa determinada forma jurídica, 4 ou, ainda, no conceito equipolente de BISCARETTI DI RUFFIA, um ordenamento jurídico. ${ }^{5}$

Com efeito, na Constituição está, em corpo inteiro, o ordenamento jurídico do Estado. Dela promanam, na sua totalidade, não só os direitos e poderes, mas também os deveres e atribuições que presidem o funcionamento do próprio regime.

Assim, pois, o estudo da questão terá de fazer-se a partir tuá-la na sua exata configuração.

\section{IV}

A descentralização federativa, entre nós, opera-se em três niveis distintos de autonomia, nos quais se situam, por ordem decrescente, a União, os Estados e os Municípios. A esses degraus de autonomia correspondem três categorias diferentes de governo, exercendo sua jurisdição no mesmo espaço territorial. Vem daí o princípio de repartição de competência, graças ao qual se tornou possível, na prática do regime, o exercício simultâneo de três jurisdições distintas sobre o mesmo território, a salvo de quaisquer conflitos.

De permeio a essa clara distribuição de autonomia política e administrativa, colocam-se os Territórios Federais.

Embora gozem do status de entidades constitutivas do Estado Federal, os Territórios não participam das franquias de autogoverno reconhecidas aos Estados-membros e aos Municípios. São, ao revés, administrados pela União, através de preposto, que exerce suas atribuições nos limites de uma base física àquela pertencente e dentro de uma estreita faixa de competência traçada em lei reguladora, de caráter especial. Neste sentido é que a administração territorial se apresenta aos estudio-

4 ROGER BONNARD - Précis de Droit Public, passim.
5 BISCARETTI DI RUFFIA - Lo Stato Democratico Moderno, passim. 
sos da matéria como simples extensão do poder de controle e da capacidade de organização da União Federal, que, inclusive, a subvenciona, mediante dotações consignadas no Orçamento Geral.

Além do mais, é de notar-se que a relação existente entre esses Territórios e a União Federal não é apenas de coordenação, mas precipuamente de subordinação, através do Ministério do Interior, cuja estrutura administrativa integram, para todos os efeitos.

Torna-se evidente, portanto, que não só a falta de autonomia, em sentido estrito, mas também a manifesta carência de meios financeiros próprios, expressa na privação do poder tributário, e ainda a absoluta ausência de capacidade de auto-organização, configuram características que por si mesmas situam os Territórios Federais no plano puro e simples da administração politicamente descentralizada.

Não é sem fundadas razões que ALIOMAR BALEEIRO afirma, de modo incisivo e peremptório:

"Os Territórios não são Pessoas de Direito Público Interno, como a União, o Distrito Federal, os Estados-membros e os Municípios. Não passam de possessões, às quais a União, por lei, querendo, poderá outorgar maior ou menor autonomia administrativa". 6

TEMISTOCLES CAVALCANTI, depois de focalizar, com base no texto constitucional, a posição desses Territórios encre as diversas entidades que compõem a estrutura do sistema federativo, acrescenta, a propósito da carência de autonomia que Ihes caracteriza:

"Esta dependência do poder central, em assuntos primordiais para a vida dos Territórios, constitui um dos sérios obstáculos ao seu desenvolvimento, dependência agravada, de muito, pela distância. Poderia ter a Constituição estabelecido certas normas que permitissem atribuir relativa autonomia administrativa aos Territórios, por meio de um sistema semelhante àquele a que obedece o funcionamento dos órgãos autárquicos". 7

6 ALIOMAR BALEEIRO - Ob. cit., pág. 121.

7 TEMISTOCLES BRANDÃO CAVALCANTI - A Constituiçăo Federal Comentada, I, pág. 71. 
Só recentemente se cogitou de equiparar os Territórios, para os efeitos legais, às entidades da administração dita indireta. A iniciativa está consubstanciada no art. $4 .^{\circ}$ do Decreto-lei n. 411 , de 8 de janeiro de 1969 , assim redigido:

"Os Territórios são unidades descentralizadas da Administração Federal, com autonomia administrativa e financeira, equiparadas, para os efeitos legais, aos órgãos de administração indireta".

Observa-se, entretanto, que essa autonomia, outorgada à guisa de conveniência, em vista das peculiaridades que cercam a administração territorial, entre as quais repontam as enormes distâncias e as dificuldades de acesso às respectivas áreas, ressente-se da necessária amplitude, incidindo apenas sobre a exígua faixa de competência que delimita as atribuições dos governadores, como prepostos, que continuam a ser, do Poder Central.

No mais, o poder de controle do Governo Federal continua a exercer-se em toda a sua plenitude, estando presente ao mencionado diploma legal, que constitui a legislação básica dos Territórios Federais, nos seguintes passos:

a) nomeação do Governador pelo Presidente da República, mediante indicação do Ministro do Interior (art. 15);

b) fixação, pelo Ministro, dos estipêndios do Governador e dos Secretários (art. 16);

c) aprovação, pelo Ministro, da proposta orçamentária (art. 18, IV), dos planos plurianuais de investimento e respectivas revisões, dos orçamentos-programas (art. 18, V), dos planos de aplicação da receita dos tributos arrecadados e de cuja distribuição participem, considerados como suplemento dos recursos atribuídos pela União aos Territórios (art. 38, parág. único), e dos planos de aplicação concernentes ao reinvestimento direto das receitas de qualquer natureza, arrecadadas pelos Territórios, excetuadas as provenientes de tributos (art. 39);

d) remessa obrigatória do relatório anual das atividades administrativas ao Ministro (art. 18, XVI); 
e) proibição, quanto ao Governador, de afastar-se do Território sem prévia ciência do Ministro (art. 19, § 1. ${ }^{\circ}$ );

f) designação, pelo Ministro, de Governador interino, nas ausências e impedimentos do efetivo (art. 19, § $3 .^{\circ}$ );

g) decretação, por lei federal, de natureza especial, dos impostos previstos (art. 37);

h) necessidade de outorga da União para a cobrança, pelos Territórios, dos tributos de cuja distribuição participem (art. 38);

i) consignação, no Orçamento Geral da União, em cada exercício, dos recursos necessários aos encargos da administração territorial (art. 40);

j) exercício das atividades financeiras sob controle direto do Ministério do Interior (art. 43);

I) obrigatoriedade da prestação de contas anual, pelo Governador, ao Ministro do Estado (art. 43, § 1..$^{\circ}$;

m) imprescindibilidade da autorização do Ministro do Interior para a instalação de Escritórios de Representação dos Territórios (art. 78).

Em contraposição, na limitada esfera de autonomia reservada aos Governadores, colocam-se as seguintes atribuições:

a) expedir decretos territoriais e demais atos necessários à administração do Território;

b) representar, juridicamente, o Território nos assuntos de interesse da administração;

c) nomear e exonerar os Secretários;

d) nomear, exonerar, aposentar e praticar os demais atos de movimentação de pessoal do quadro próprio do Território, assim como aplicar as penalidades previstas em lei;

e) promover a instauração de comissão de inquérito para apurar a responsabilidade de funcionário em exercício no Território; 
balhista;

f) admitir e dispensar servidores sob o regime tra-

g) nomear e exonerar os Prefeitos;

h) delegar competência para a prática de atos administrativos.

Mais não seria preciso a fim de mostrar que se trata, no caso, tipicamente, de uma autonomia por equiparação e não por natureza própria.

\section{VI}

O controle da aplicação, pelos Territórios, de recursos de fundos especiais, assume, pois, aspectos peculiares, que de resto correspondem à singularidade da posição ocupada por essas entidades descentralizadas no sistema federativo.

Em atinência aos Estados e Municípios, o mecanismo funciona como expressão do controle financeiro da União Federal sobre recursos distribuídos a entidades dotadas de autonomia política e administrativa, e, como tais, atuantes em esferas de competência próprias e perfeitamente diferenciadas.

Quanto aos Territórios Federais, porém, o problema se desenha no quadro geral do controle exercido pela União sobre os órgãos integrantes de sua estrutura administrativa.

Sob este aspecto, não há como situar no plano restrito da fiscalização financeira o controle a cargo dos diversos entes personalizados da administração federal, relativamente à aplicação desses fundos, sobretudo em face da vigente Reforma Administrativa, que, sobrevindo a estes, trouxe consigo a institucionalização dos sistemas de atividades auxiliares, dentro de uma nova filosofia de ação do Governo Federal.

\section{VII}

No regime instituído pelo Decreto-lei $n .{ }^{\circ} 200$, de 25 de fevereiro de 1967, o controle das atividades governamentais representa a contrapartida necessária ao princípio de descentralizacão, amplamente adotado como norma geral de exercício da função executiva. Não é outra, aliás, a razão pela qual esse controle, erigido em sistema, abrange todos os aspectos da ativi- 
dade executiva, estendendo-se a todos os níveis e setores da hierarquia administrativa.

A regra está consubstanciada no art. 13 daquele diploma legal, que estatui:

"O controle das atividades da Administração Federal deverá exercer-se em todos os níveis e em todos os órgãos, compreendendo, particularmente:

a) o controle, pela chefia competente, da execução dos programas e da observância das normas que governam a atividade específica do órgão controlado.

b) o controle, pelos órgãos próprios de cada sistema, da observância das normas gerais que regulam o exercício das atividades auxiliares;

c) o controle da aplicação dos dinheiros públicos e da guarda dos bens da União pelos órgãos próprios do sistema de contabilidade e auditoria".

Mais tarde, o Decreto $n{ }^{\circ} 67.090$, de 20 de agosto de 1970 , no seu art. $1 . \circ$, tratou de explicitar a matéria, e o fez com a seguinte redação:

"A fiscalização das atividades dos órgãos e entidades da Administração Federal, direta ou indireta, será exercida em todos os níveis:

I - pelas chefias competentes, quanto à execução dos objetivos do órgão sob sua responsabilidade, observadas as normas aplicáveis;

II - pelos órgãos próprios de cada sistema, quanto à observância das normas que regulam o exercício das atividades auxiliares;

III - pelas Inspetorias-Gerais de Finanças dos Ministérios Civis e órgãos equivalentes da Presidência da República, dos Ministérios Militares e dos Poderes Legislativo e Judiciário, quanto à aplicação dos dinheiros e valores públicos e à guarda dos bens da União".

Compreende-se que a lei fixa, por esse modo, o princípio geral de competência quanto à fiscalização das atividades admi- 
nistrativas, sem exceção de qualquer órgão ou entidade, dos Poderes da República.

\section{VIII}

Evidenciam-se, portanto, na sistemática legal, três modalidades distintas de controle interno da administração, a saber:

a) o programático - exercido pelas chefias competentes no tocante às normas aplicáveis à execução dos projetos e atividades constantes da programação estabelecida;

b) o administrativo - a cargo dos órgãos específicos de cada sistema, quanto ao cumprimento das normas reguladoras das atividades auxiliares;

c) o financeiro - desempenhado pelos órgãos próprios do sistema de contabilidade e auditoria, no que tange à aplicação dos dinheiros e valores públicos, assim como à guarda dos bens da União.

Cumpre ressaltar que esses diferentes tipos de controle interno se caracterizam por atuarem em faixas nitidamente diferenciadas da atividade administrativa. Assim é que se exercem, a salvo de eventuais conflitos, simultânea e independentemente. Não contradizem nos seus objetivos essenciais, mas, pelo contrário, harmonizam-se entre si, e se ajustam, por fim, aos principios fundamentais da própria Reforma Administrativa.

Acaso não se configurassem, na espécie, modalidades distintas de controle, é certo que careceria de sentido a regra contida no art. $1 .^{\circ}$, parágrafo único, do Decreto $n .^{\circ} 67.090 / 70$, assim concebida:

"A fiscalização prevista nos itens I e II será exercida independentemente e não eliminará a constante do inciso III".

Entende-se tanto mais o sentido desse dispositivo, quanto se torna claro que a múltipla incidência da mesma espécie de controle sobre as mesmas contas, em detrimento da competência específica do órgão próprio do sistema de fiscalização financeira, importaria em flagrante atentado ao preceito fixado no art. 14 do Decreto-lei $n .^{\circ} 200 / 67$, verbis: 
"O trabalho administrativo será racionalizado mediante simplificação de processos e supressão de controles que se evidenciarem como puramente formais ou cujo custo seja evidentemente superior ao risco".

E mais, à norma do art. $30, \S 3 .^{\circ}$, que dispõe:

“É dever dos responsáveis pelos diversos órgãos competentes dos sistemas atuar de modo a imprimir o máximo rendimento e a reduzir os custos operacionais da Administração".

\section{IX}

Por seu turno, o sistema de controle financeiro tem como órgão central a Inspetoria-Geral de Finanças do Ministério da Fazenda e como órgãos setoriais as Inspetorias-Gerais de Finanças dos demais Ministérios.

É o que se vê do art. 31 , parágrafo único:

"O órgão central do Sistema de Orçamento e do Sistema de Administração Financeira, Contabilidade e Auditoria, serão, respectivamente, a Secretaria-Geral, do Ministério do Planejamento e Coordenação Geral e a Inspetoria-Geral de Finanças, do Ministério da Fazenda".

Observa-se, ademais, que tanto o órgão central quanto os órgãos setoriais funcionam, nas áreas respectivas, em nome e sob a direção do Ministro de Estado competente, graças ao princípio da supervisão ministerial, que se converte em fulcro de todo o sistema de controle.

Neste sentido, dispõe, de modo claro e preciso, o art. 20:

"O Ministro de Estado é responsável, perante o Presidente da República, pela supervisão dos órgãos da Administração Federal enquadrados em sua área de competência.

Parágrafo único - A supervisão ministerial exercerse-á através da orientação, coordenação e controle das atividades dos órgãos subordinados ou vinculados ao Ministério, nos termos deste Decreto-lei". 
E acrescenta o art. 23, após definidos, no dispositivo anterior, os órgãos do sistema:

"Os órgãos a que se refere o item I, do art. 22, têm a incumbência de assessorar diretamente o Ministro de Estado e, por força de suas atribuições, em nome e sob a direção do Ministro, realizar estudos para a formulação de diretrizes e desempenhar funções de planejamento, orçamento, orientação, coordenação, inspeção e controle financeiro, desdobrando-se em:

\section{II - uma Inspetoria-Geral de Finanças".}

Segue-se daí que as Inspetorias-Gerais de Finanças, atuando em nome e sob a direção do Ministro de Estado o fazem, ao mesmo tempo, como órgã̃os setoriais do sistema de administração financeira.

Resulta evidente, assim, que o controle financeiro dos órgãos subordinados ou vinculados envolve a responsabilidade do Ministro de Estado e se exerce através do órgão setorial do sistema. Esse controle, sob pena de frustrar-se nos seus objetivos essenciais, terá de abranger toda a contabilidade desses órgãos, inclusive no que concerne à aplicação dos recursos provenientes dos fundos especiais. Realmente, só deste modo estará o Ministro capacitado a desempenhar a função que Ihe é cometida de aquilatar do grau de eficiência da ação administrativa desses órgãos e da aptidão dos respectivos dirigentes, como quer a lei, quando preceitua que o principal objetivo da supervisão ministerial consiste em "avaliar o comportamento administrativo dos órgãos supervisionados e diligenciar no sentido de que estejam confiados a dirigentes capacitados". 8

\section{$\mathbf{X}$}

Essas considerações levam à clara percepção de que, carentes de competência para o exercício autônomo do poder tributário e da capacidade para auto-organizar-se, os Territórios Federais estão sujeitos ao inteiro controle do Governo da União, por intermédio do Ministério do Interior. Assim sendo, vois tipos de controle se exercem, simultânea e independentemente, sobre os recursos por eles aplicados à conta dos fundos especiais:

DECRETO-LEI N.0 200/67, art. 25, V. 
a) o controle programático, a cargo dos órgãos indicados nos respectivos atos de criação; e

b) o controle financeiro, sob a responsabilidade do órgão próprio do sistema de administração financeira, contabilidade e auditoria.

Não é preciso insistir no fato de que esses controles atuam dentro de suas respectivas áreas de competência, claramente definidas e delimitadas na legislação básica da Reforma Administrativa.

O controle financeiro, pois, é exercido pela Inspetoria-Geral de Finanças do Ministério do Interior, na sua qualidade de órgão setorial do sistema. A esse órgão compete, ainda, proceder à tomada de contas anual na área de competência do Ministério e expedir o certificado de auditoria pertinente, para efeito do competente pronunciamento do Ministro de Estado.

Está, de fato, no art. 82 do Decreto-lei n. ${ }^{\circ}$ 200/67:

"As tomadas de contas serão objeto de pronunciamento expresso do Ministro de Estado, dos dirigentes dos órgãos da Presidência da República ou de autoridade a quem estes delegarem competência, antes do seu encaminhamento ao Tribunal de Contas, para os fins constitucionais e legais".

A regra do artigo é completada com as disposições do seu parágrafo 1. , que preceitua:

"A tomada de contas dos ordenadores, agentes recebedores, tesoureiros ou pagadores será feita no prazo máximo de 180 (cento e oitenta) dias do encerrramento do exercício financeiro pelos órgãos encarregados da contabilidade analítica e, antes de ser submetida ao pronunciamento do Ministro de Estado, aos dirigentes de órgãos da Presidência da República ou da autoridade a quem estes delegarem competência, terá sua regularidade certificada pelo órgão de auditoria".

Acresce que o certificado de auditoria expedido em relação às contas da administração territorial deve abranger, necessariamente, os recursos dos fundos especiais por ela aplicados, 
pelo simples fato de que nenhum aspecto da administração financeira dos órgãos ministeriais, subordinados ou vinculados, poderia escapar à análise do órgão responsável pelas tomadas de contas, sem prejuízo das suas atribuições especificas, e até mesmo porque as peculiaridades que revestem o mecanismo de contabilização desses recursos impõem que seu exame se processe sob o prisma global das despesas realizadas.

Esse certificado, aliás, representa o próprio controle financeiro da União, na medida em que a Inspetoria-Geral de Finanças atua como órgão setorial do sistema de administração financeira, contabilidade e auditoria do Governo Federal.

Além disso, o controle financeiro a cargo, especificamente, da Inspetoria-Geral de Finanças, não elide, mas antes completa a função precípua de controle programático atribuída, em cada caso, nos termos das leis instituidoras desses fundos especiais, a entes personalizados da administração federal. Consoante ficou demonstrado linhas atrás, aí se configuram duas modalidades de controle, exercendo-se em planos diferentes e com objetivos distintos, como instrumentos de avaliação da regularidade e da eficiência da atividade administrativa, sob os aspectos relacionados, de um lado, com a efetiva aplicação dos recursos distribuidos, e, do outro, com a observância da programação estabelecida.

\section{CONCLUSÃO}

Em síntese, o estudo da matéria, segundo os itens anteriores, conduz às seguintes conclusões:

I - Os fundos especiais, como receita vinculada, submetem-se ao controle de entes personalizados da administração federal, indicados, geralmente, na própria lei instituidora, em razão da especificidade da matéria.

II - Quando distribuídos aos Territórios Fed
estes aplicados, ficam sujeitos a duplo controle:

a) o que se exerce através dos órgãos encarregados do cálculo e distribuição das respectivas cotas, bem como da fiscalização dos projetos e atividades constantes da programação estabelecida; e

b) o que se efetiva por intermédio da Inspetoria-Geral de Finanças do Ministério do Interior, no exercício de suas 
funções específicas de fiscalização dos dinheiros públicos manipulados por órgãos subordinados ou vinculados a essa Secretaria de Estado.

III - O controle exercido pelos órgãos indicados nas leis de criação desses fundos especiais é de caráter programático e nessa qualidade se atém à verificação quanto ao cumprimento, pelo órgão controlado, das normas reguladoras da execução dos projetos e serviços compreendidos na respectiva programação.

IV - O controle a cargo do órgão setorial do sistema de administração financeira, contabilidade e auditoria é de natureza especificamente financeira e como tal visa a constatar a efetiva aplicação dos recursos de qualquer procedência no âmbito de jurisdição administrativa do Ministério, encarados esses recursos nos seus aspectos contábeis de receita e despesa públicas, em si mesmas.

V - Em se tratando de controles distintos e independentes, o exercício de um deles não exclui o do outro, nem o anula, mas, pelo contrário, um e outro se ajustam e se completam, em face da sistemática legal da Reforma Administrativa.

VI - A tomada de contas anual constitui processo típico do controle a cargo dos órgãos do sistema de administração financeira, contabilidade e auditoria, e, assim sendo, o certificado de auditoria expedido, nessa oportunidade, pela Inspetoria-Geral de Finanças, consubstancia o próprio controle financeiro da União, excluindo, na sua especificidade, a concorrência de controles afins, por parte de órgãos estranhos ao sistema.

VII - Isto posto, a expedição do certificado de auditoria, no tocante às tomadas de contas dos Territórios Federais, nelas incluídos os recursos provenientes de fundos especiais, deve caber ao órgão setorial do sistema de controle financeiro do Ministério do Interior, ou seja, a sua Inspetoria-Geral de Finanças, que detém competência específica e intransferivel para tanto, razão por que, inclusive, no seu laudo se apóia o Ministro de Estado para exarar o pronunciamento que lhe é exigido, nos termos do art. 82, § $1 .^{\circ}$, do Decreto-lei n. ${ }^{\circ}$ 200/67. 


\section{TEMA SEGUNDO}

\section{O controle das sociedades de economia mista constituídas pelos Territórios Federais}

As sociedades de economia mista configuram uma das formas de interferência do Poder Público nas atividades da empresa privada. Por extensão, também se pode dizer que constituem uma das técnicas de intervenção do Estado na ordem econômica.

Os fins e a oportunidade dessa intervenção podem ser discutidos sob o enfoque de diferentes concepções doutrinárias, mas, de um modo ou de outro, as opiniões convergem para o entendimento de que ela responde à necessidade de preservar o interesse público, por definição presente a esse tipo de sociedade anônima.

Em sentido lato, a sociedade de economia mista não é mais do que uma sociedade anônima organizada mediante a participação acionária do Estado, que nela aparece, pelo menos em teoria, como simples capitalista, em pé de igualdade aos acionistas particulares. Trata-se, em última análise, de uma fórmula jurídica e financeira, através da qual se associam capitais públicos e capitais privados para a consecução de objetivos que se colocam, por sua natureza, ao nível das exigências do desenvolvimento econômico e social do país.

II

A presença do Poder Público, como acionista, tem suscitado Sérias controvérsias de caráter doutrinário, no que concerne à conceituação jurídica desse tipo sui generis de sociedade anônima. 
FLEINER, por exemplo, vê na expressão "economia mista" tão-somente a indicação de que se acham reunidos, no caso, fundos públicos e capitais privados, com vistas à exploração de uma atividade econômica, e por isso lhe nega qualquer noção juridica. ${ }^{9}$

RIPERT, por seu turno, entende que essa associação de capitais públicos e privados "em sociedades constituidas ao sabor das circunstâncias", 10 traduzem apenas "um tímido desejo de socialização conciliadora", 11 além de se converterem em fator de perturbação da vida das sociedades mercantis. ${ }^{12}$

Situado no mesmo ângulo de observação, FALLA identifica as origens dessa instituição "nos tímidos ensaios realizados em diversos países para compatibilizar o princípio econômico do "laissez-faire" com a necessidade do estímulo estatal a certas obras e empresas de interesse público". ${ }^{13}$

JOLLY, que divisava nessas sociedades um exemplo de interpretação do direito público e do direito privado, salientava que essa simbiose constituía um compromisso de duas concepções jurídicas, que levava, na sua prática, pela aplicação do direito privado às pessoas jurídicas de direito público, à desnaturalização das atribuições funcionais do Estado, que passava a viver a vida civil e comercial das pessoas privadas. ${ }^{14}$

RAFAEL BIELSA, partindo da concepção de que esse tipo de sociedade anônima consubstancia "um ensaio de aplicação de formas combinadas", termina por firmar a opinião de que a sua configuração jurídica depende, em cada caso, do regime legal pertinente. E conclui:

"A determinação, pois, do caráter jurídico destas entidades só pode ou deve fazer-se com referência aos elementos constitutivos essenciais da sociedade ou empresa". 15

Por outro lado, adotando o ponto de vista esposado por JOLLY ("el citado autor hace notar, con razón, que esta desnatu-

\footnotetext{
9 FRITZ FLEINER - Instituciones de Derecho Administrativo, pág. 102.

10 GEORGES RIPERT - O Regime Democrático e o Direito Civil Moderno, pág. 268.

11 GEORGES RIPERT - Aspecto Jurídico do Capitalismo Moderno, pág. 54.

12 GEORGES RIPERT - Le Déclin du Droit, pág. 59.

13 GARRIDO FALLA - Tratado de Derecho Administrativo, П, pág. 538.

14 Apud RAFAEL BIELSA - Derecho Administrativo, pág. 506.

15 RAFAEL BIELSA - Ob. cit., págs, 505/506.
} 


\section{ralización de las atribuciones funcionales del Estado, es tanto} más peligrosa en cuanto se realiza a costa de la autoridad del próprio Estado" - ob. cit., pág. 508), o mestre argentino aduz:

"A Administração pública não pode nem deve ser um simples acionista. Essa atitude exclusivamente particular, implica em desertar de sua missão jurídico-social, no que respeita à prestação de serviços públicos. O Estado, ou mais propriamente a Administração Pública, intervém desde o começo da entidade mista (desde sua constituição e regulamentação, etc., até a fiscalização). Ademais, a Administração pública não renuncia ao poder de controlar, que é manifestação do poder administrativo e que significa um controle distinto daquele que exerce o simples acionista, segundo o direito comum, regido neste particular pelo Código comercial". 16

\section{III}

Entre nós, como nota MIRANDA VALVERDE, "as sociedades de economia mista têm sido criadas por leis especiais, as quais contêm sempre disposições derrogatórias do direito comum, a fim de assegurar ao Estado o controle absoluto sobre a administração da sociedade". ${ }^{17}$

Com efeito, a opinião dominante no campo doutrinário está espelhada em conceito emitido por CAIO TÁCITO, segundo o qual "se a participação estatal representa mero investimento ou garantia especial, se não corresponde à atribuição de um encargo de serviço público, a presença do Estado não elidirá o caráter estritamente privado da sociedade comercial". ${ }^{18}$

Nessa mesma linha de pensamento, VICENTE RÁO ressalta que o Estado "ao participar das chamadas sociedades de economia mista, sempre o faz criando para si, por lei ou contrato, uma situação especial, impondo diretrizes ou participando, predominantemente, de sua direção, o que confere a estas sociedades, embora formalmente sujeitas às leis do direito privado,

17 RAFAEL BIELSA - Ob. cit., pág. 508.

17 TRAJANO DE MIRANDA VALVERDE - Sociedades por Açōes, I, págs. 46/47.

8 CAIO TACITO - "Sociedades Comerciais e Fundaçס̋es do Estado", in Rev. Forense, n. ${ }^{2}$ 205, pág. 417. (No mesmo sentido: WALDEMAR FERREIRA, Trat. de Dir. Com., V. 334/336: HAROLDO VALADÃO Parecer, in Rev. Dir. Adm., n. ${ }^{\circ} 48,582$; HELY LOPES MEIRELLES, Dir MUn Bras, 250; TÉÓFILO DE AZEVEDO SANTOS, "As SOC. de EC. Mista no Dir. Bras.", págs, 29 e segs.; OSCAR SARAIVA, Parecer, in Rev. Forense, n. 0 100, pág. 234. 
uma natureza peculiar, resultante da circunstância de executarem fins ou serviços administrativos, ou estatais". 19

Sem afastar-se dessa concepção, MIGUEL REALE coloca o problema nas suas exatas dimensões, ao escrever:

"Não há dúvida que não basta a participação acionária do Poder Público, ainda que lhe caiba o controle acionário, para converter uma sociedade em economia mista, prevalecendo na doutrina o entendimento de que só é possível o surgimento desta mediante a conjugação desses três fatores:

a) autorização legal para instituí-la, visto ser vedado ao Poder Executivo aplicar e movimentar bens e dinheiros públicos, sem a prévia autorização do Poder Legislativo (exigência formal);

b) finalidade pública da entidade, ultrapassando o plano do mero investimento de natureza privada (exigência teleológica);

c) controle administrativo, que pode assumir as mais variadas formas, desde a tutela direta até os meios indiretos de orientação ou fiscalização (exigências de tute-

\section{IV}

O controle do Estado em relação às sociedades de economia mista reveste aspectos peculiares, uma vez que se exerce sob duas modalidades distintas:

a) o controle interno, efetivado por intermédio de representantes seus nos cargos de direção da empresa, e que se traduz em termos de poder de decisão; e

b) o controle externo, em geral a cargo de órgão sītuado na área da política econômico-financeira do governo.

No primeiro caso, o controle se exerce segundo as regras do direito comum, visto que o Poder Público se apresenta, em princípio, como simples membro da sociedade, ao lado dos acionistas particulares. No segundo, ele configura o próprio poder de

19 VICENTE RAO - O Direito e a Vida dos Direitos, I, pág. 361.

20 MIGUEL REALE - Direito Administrativo (Estudos e Pareceres), pág. 36.

R. Serv. Púb!., Brasilia, 108 (2): mai./ago. 1973 
tutela do Estado, exercitando-se com vistas à preservação do interesse público, que de resto serve de fundamento e limite à ação fiscalizadora.

Poder-se-ia dizer, com referência a esses controles, que entre eles se estabelece a mesma espécie de equilibrio existente nos vasos comunicantes, ou seja, que a extensão do controle externo varia em função da amplitude do controle interno.

Tal, porém, não ocorre, seja majoritária ou minoritária a participação acionária do Poder Público. Na realidade, como "a administração das sociedades de economia mista é regulada pela lei que cria a empresa", consoante observa ARNALD WALD, ${ }^{21}$ e essa legislação especial, conforme salienta MIRANDA VALVERDE, importa às mais das vezes na derrogação dos princípios do direito privado aplicáveis, ${ }^{22}$ resulta que não só o controle interno ultrapassa, em regra, os limites previstos no direito comercial, como também o controle externo cada vez se torna mais amplo, na medida em que se trata de proteger os fundos públicos investidos na empresa.

\section{V}

No Estado Moderno, o controle administrativo já não se expressa em termos de limitações impostas às atividades das empresas, mas, ao invés, tem por objetivo essencial assegurar o equilíbrio das relações econômicas operadas ao nível dos interesses nacionais. Nesse sentido, DEMICHEL entende que no Estado dito do
Bem-Estar (Welfare state), responsável "pela salvaguarda do equilíbrio econômico e social da nação" e como tal detentor "do poder de determinar a forma e os meios desse equilíbrio", não se admite mais "que a liberdade por princípio deixada aos organismos privados se permita colocar esse equilíbrio em perigo".

E acrescenta:

"Puisque l'ordre économique et social ne s'etablit pas de lui-même, la puissance de le promouvoir et les particuliers doivent concourir à cette promotion. Si l'État les contrôle, ce sera pour s"assurer que ce concours se realise dans les faits. 
Le contrôle change alors de visage: l'administration ne se contente plus d'interdire, elle prescrit. Elle pénètre dans le fonctionnement de l'organisme, influe sur ses décisions. Le contrôle n'est plus une limite à l'intérieur de daquelle les organismes privés peuvent agir librement, il est un ensemble de directives qui orientant leur action". ${ }^{23}$

\section{VI}

No sistema do nosso direito positivo, além da fiscalização prevista nas respectivas leis instituidoras, as sociedades de economia mista estão submetidas ao controle da Comissão de Defesa dos Capitais Nacionais (CODECAN), reorganizada pelo Decreto-lei n. ${ }^{\circ} 147$, de 3 de fevereiro de 1967.

Esse diploma legal, no seu art. 39, determina:

"A Comissão de Defesa dos Capitais Nacionais (CODECAN) do Ministério da Fazenda passará a ser o órgão de deliberação coletiva anexo à Procuradoria-Geral da Fazenda Nacional e terá por finalidade precípua a defesa e o controle dos interesses da União nas sociedades de cujo capital o Tesouro Nacional participe, diretamente ou através de qualquer outra entidade.

Parágrafo único - O controle exercido pela CODECAN abrangerá as empresas públicas e quaisquer outros organismos de cujo capital, no todo ou em parte, seja titular o Tesouro Nacional, e estender-se-á às sociedades de que sejam acionistas os entes definidos neste artigo".

$\mathrm{O}$ art. 43 disciplina as obrigações das entidades abrangidas pelo alcance daquele dispositivo e tem a seguinte redação:

"As entidades indicadas no artigo 39 e seu parágrafo único são obrigadas a:

I - prestar à CODECAN toda a colaboração que lhes for solicitada para o bom desempenho das suas atribuições, inclusive a designação de funcionários e auxiliares graduados que mantenham contacto e prestem auxílio à
Comissão; 
II - remeter ao referido órgão, com antecedência mínima de 30 (trinta) dias, da data das respectivas assembléias-gerais, a ordem do dia a estas referente, acompanhada de cabal justificativa, inclusive documental, para os diversos assuntos a serem tratados naquelas assembléias;

III - fornecer os dados que Ihes forem solicitados, bem como as sugestões que tiverem, para a elaboração do relatório anual da CODECAN".

vero art. 45 prevê a representação do órgão financeiro do Governo Federal nos conselhos fiscal e consultivo dessas mesmas entidades, e o faz nos seguintes termos:

"Nos Conselhos Fiscal e Consultivo das entidades referidas no artigo 39 e seu parágrafo único, haverá, salvo disposição legal em contrário, pelo menos, um membro a ser eleito por indicação do Tesouro Nacional, devendo recair a escolha em funcionário do Ministério da Fazenda, de comprovada competência e idoneidade, sem prejuizo do exercício do seu cargo ou função".

Esses dispositivos legais não deixam a mais leve dúvida quanto à natureza e extensão da atividade controladora atribuída à CODECAN. Na verdade, esse controle é de molde a penetrar toda a estrutura das entidades abrangidas, dentro da concepção, a que se refere DEMICHEL, de que, modernamente, a administração "penetra no funcionamento do organismo e influi nas suas decisões", por isso que o controle "não é mais um limite dentro do qual os organismos privados podem agir livremente", mas, antes, "um conjunto de diretrizes que orientam a ação desses organismos".

O controle a cargo do novo colegiado alcança todas as sociedades de cujo capital participe a União, mediante a aplicação de fundos seus, diretamente, pelo Tesouro Nacional, ou indire-
tamente, por organismo que manipule dinheiro do erário federal.

\section{VII}

0 Dúvidas, porém, quanto à matéria, começaram a surgir com que subme do Decreto-lei n. 200, de 25 de fevereiro de 1967 , tes Mubmeteu essas mesmas entidades ao controle dos diferenMinistérios, de acordo com as seguintes disposições: 
"Art. 4. - A Administração Federal compreende:

I - A Administração Direta, que se constitui dos serviços integrados na estrutura administrativa da Presidência da República e dos Ministérios;

II - A Administração Indireta, que compreende as seguintes categorias de entidades, dotadas de personalidade jurídica própria:

a) Autarquias;

b) Empresas Públicas;

c) Sociedades de Economia Mista.

$\S 10^{\circ}$ - As entidades compreendidas na Administração Indireta consideram-se vinculadas ao Ministério em cuja área de competência estiver enquadrada sua principal atividade.

Art. 19 - Todo e qualquer órgão da Administração Federal, direta ou indireta, está sujeito à supervisão do Ministro de Estado competente, excetuados unicamente os órgãos mencionados no artigo 32 , que estão submetidos à supervisão direta do Presidente da República.

Art. 20 - O Ministro de Estado é responsável, perante o Presidente da República, pela supervisão dos órgãos da Administração Federal enquadrados em sua área de competência. A supervisão ministerial exercer-se-á através da orientação, coordenação e controle das atividades dos órgãos subordinados ou vinculados ao Ministério, nos termos deste Decreto-lei.

Art. 26 - No que se refere à Administração Indireta, a supervisão ministerial visará a assegurar, essencial-
mente:

I - a realização dos objetivos fixados nos atos de constituição da entidade; 
II - a harmonia com a política e a programação do Governo no setor de atuação da entidade;

III - a eficiência administrativa;

IV - a autonomia administrativa, operacional e financeira da entidade".

\section{VIII}

0 confronto entre os dois citados decretos-leis revela, desde logo, que, enquanto o de número 147 prevê o controle, pela CODECAN, das "sociedades de cujo capital o Tesouro Nacional participe, diretamente ou através de qualquer outra entidade ", o de número 200, ao mesmo tempo que inclui essas sociedades nos quadros da Administração Indireta, cuida de submetê-las, por força do princípio básico da supervisão ministerial, convertido em fulcro de todo o sistema de fiscalização do desempenho governamental, à orientação, coordenação e controle do "Ministério em cuja área de competência estiver enquadrada sua principal atividade".

Efetivamente, a contradição essencial que à primeira vista parecia ocorrer entre os decretos-leis em causa, na parte referente aos dispositivos transcritos, gerou a impressão de que, do do o de número 200 posterior ao de número 147 , teria havido, necessariamente, derrogação deste último, quanto à matétemátisamente regulada pelo primeiro, ao estabelecer a sistemática legal da Reforma Administrativa Todavia, o estudo mais acurado dos textos em confronto,
levado a efeito sob a perspectiva mais ampla dos princípios que regem a nova organização administrativa do Governo Feque , conduz em definitivo ao afastamento de qualquer dúvida hermedesse, nos limites do razoável, aflorar no espírito do hermeneuta.

\section{IX}

Se é certo que as sociedades de economia mista estão efompreendidas no âmbito da administração indireta, para os guartos da supervisão ministerial, não é menos certo que elas guardam, na sua configuração específica, as características tra-
dicionais, que as distinguem tanto das autarquias quanto das 
empresas públicas. Das primeiras, diferenciam-se, fundamentalmente, pela personalidade jurídica de direito privado e pela natureza mercantil de suas atividades. Das segundas, separam-se, sob o aspecto conceitual, pela forma de sociedade anônima, que a lei expressamente lhes impõe, e também pela associação de fundos públicos e capitais privados na constituição do capital social (art. 5..$^{\circ}$ do Dec.-lei n. ${ }^{\circ}$ 200/67).

A posição da sociedade de economia mista, pois, em face do controle administrativo, singulariza-se, no quadro geral das entidades da Administração Indireta, por ser a única, entre todas, que associa, na sua constituição, capitais públicos e privados. Ao lado da empresa pública, à qual, não obstante constituída apenas com fundos públicos, se asseguram condições de funcionamento idênticas às do setor privado, as sociedades de economia mista fazem jus a tratamento especial.

É assim que dispõe, no seu art. 27 , parágrafo único, o Decreto-lei n. $200 / 67$ :

"Assegurar-se-á às empresas públicas e às sociedades de economia mista condições de funcionamento idênticas às do setor privado, cabendo a essas entidades, sob a supervisão ministerial, ajustar-se ao plano geral do Go-

\section{$\mathbf{X}$}

O controle administrativo das sociedades de economia mista se exerce, predominantemente, como de resto é curial, através do órgão específico da política econômico-financeira do Governo. Realmente, não se cogita, no caso, apenas de verificar a simples regularidade quanto à aplicação de fundos públicos, ou de avaliar a eficiência administrativa, em confronto com os objetivos fixados nos atos de constituição da sociedade, mas também, e sobretudo, de orientar, coordenar e controlar as suas atividades, sob todos os aspectos, em consonância com as diretrizes da política econômico-financeira formulada para o país, em seu conjunto. No primeiro desses aspectos, configura-se 0 controle decorrente do princípio básico da supervisão ministerial. No segundo, manifesta-se o controle específico do órgão ceira do Governo Federal. 
Não há, por conseguinte, incompatibilidade entre os preceitos estabelecidos pelos diplomas legais em questão, uma vez que um e outro definem áreas de controle perfeitamente diferenciadas. O controle a cargo da CODECAN, preceituado pelo Decreto-lei $n .^{\circ} 147$, visa, estritamente, "à defesa e ao controle dos interesses da União nas sociedades de cujo capital participe, direta ou indiretamente, o Tesouro Nacional", enquanto o controle previsto pelo Decreto-lei $n .^{\circ} 200$ se exerce em função das atribuições conferidas aos sistemas de atividades auxiliares, como tais.

\section{$\mathbf{X I}$}

Nos termos do art. 39, parágrafo único, do Decreto-lei n. 147 , o controle exercido pela CODECAN "abrangerá as empresas públicas e quaisquer outros organismos de cujo capital, no todo ou em parte, seja titular o Tesouro Nacional", e estender-se-á às sociedades de que sejam acionistas os entes referidos no caput do artigo, isto é, qualquer outra entidade que manipule fundos pertencentes à União.

É bem de ver que a esse controle não escapam, nem mesmo poderiam escapar, as sociedades de economia mista, ainda que constituídas nos Territórios Federais, mediante a participação acionária destes.

Meras entidades descentralizadas e como tal estruturadas por via de lei especial, e mantidas, à míngua de poder trito Geral, pela União, que as administra por intermédio de preposto $\mathrm{e}$ as tem sob inteira subordinação, através do Ministério do Interior - os Territórios Federais se enquadram entre as entidades a que se reporta o art. 39 do Decreto-lei $n .^{\circ} 147 / 67$. Assim sendo, não há como fugir à conclusão de que as sociedades de economia mista por eles constituídas estão sujeitas ao cumprimento das obrigações estatuídas no art. 43 do mesmo diploma legal.

\section{XII}

Estabelecido esse entendimento, torna-se oportuno atentar para o fato de que, na conformidade do parágrafo único, letra b, do art. 26 do Decreto-lei n. 200 , a cada Ministro de Estado incumbe designar o representante da União nas assembléias-ge- 
rais das entidades jurisdicionadas ao respectivo Ministério. Esse dispositivo tem a seguinte redação:

"Art. 26

Parágrafo único - A supervisão exercer-se-á mediante adoção das seguintes medidas, além de outras estabelecidas em regulamento:

b) designação, pelo Ministro, dos representantes do Governo Federal nas Assembléias-Gerais e órgãos de administração ou controle da entidade".

Neste particular, o Decreto-lei $n .^{\circ} 200$ regulou inteira e diversamente a matéria contida no art. $1 .^{\circ}$, item $\mathrm{V}$ e no art. 23 , ambos do Decreto-lei n. 147 , que prescrevem:

"Art. $10^{\circ}$ - A Procuradoria-Geral da Fazenda Nacional (P.G.F.N.) é o órgão jurídico do Ministério da Fazenda, diretamente subordinado ao Ministro de Estado, dirigido pelo Procurador-Geral da Fazenda Nacional e tem por finalidade privativa:

V - representar a União nas assembléias-gerais das sociedades de economia mista e em outras entidades de cujo capital o Tesouro Nacional participe.

Art. 23 - Na representação da União nas assembléias-gerais das sociedades de economia mista e em outras entidades de cujo capital o Tesouro Nacional participe, o Procurador-Geral da Fazenda Nacional, ou o Procurador da Fazenda Nacional, quando por aquele lhe for delegada competência, procederá estritamente de acordo com as instruções que Ihe forem transmitidas pelo Ministro da Fazenda".

Nestas condições, resulta patente a revogação sofrida por esses dispositivos, tendo em vista que a matéria de que trata foi regulada, de modo diverso e integral, pelo art. 26 do Decreto-lei n. ${ }^{\circ} 200 / 67$. 


\section{XIII}

Resta considerar, ainda, no interesse da completa elucidação do assunto, que o Decreto-lei n. ${ }^{\circ} 147$, ao tratar, no seu artigo 40, item VI, da constituição da CODECAN, prevê, entre os membros desta, um representante de cada Ministério interessado.

Assim reza o dispositivo:

"Art. 40 - Além do Procurador-Geral, seu presidente nato, a CODECAN compor-se-á dos seguintes membros:

$\mathrm{VI}$ - um representante de cada um dos Ministérios a que se vinculam as entidades referidas no art. 39 e seu parágrafo único;"

Claro está que, no caso em estudo, o Ministério do Interior, em cuja estrutura administrativa se integram os Territórios Federais acionistas das sociedades aqui consideradas, deve representar-se na CODECAN. Todavia, há conveniência em que essa representação esteja a cargo do mesmo funcionário que, na forma do art. 26, parágrafo único, letra $\mathbf{b}$, do Decreto-lei n.ं200/67, for designado para representar a União nas assembléias-gerais das entidades vinculadas a essa mesma Secretaria de Estado.

De igual modo, em virtude de certas atribuições similares existentes nas áreas de controle definidas à CODECAN e aos Ministérios, respectivamente, consoante os preceitos legais que as disciplinam, torna-se desejável que as relações entre as entidades controladas e aquele colegiado sejam exercitadas por intermédio do representante do Ministério do Interior, de acordo com instruções da Inspetoria-Geral de Finanças.

\section{CONCLUSÃO}

Em suma, as considerações expendidas ao longo dos itens anteriores levam à seguinte conclusão:

1. Os Territórios Federais, como entidades meramente descentralizadas da Administração Federal, e, nessa qualidade, 
mantidos através de dotações globais consignadas no Orçamento da União, estão compreendidos na expressão "qualquer outra entidade", do art. 39 , in fine, do Decreto-lei $n .^{\circ} 200 / 67$.

2. Assim sendo, as sociedades de economia mista constituídas nesses territórios, e de cujo capital eles participem, colocam-se ao alcance da regra contida no parágrafo único do mesmo artigo e como tal estão sujeitas ao cumprimento das obrigações estatuídas nos arts. 43 e 45 do citado diploma legal.

\section{CONCLUSÃO GERAL}

A exposição dos temas em estudo enseja, por sua vez, a seguinte conclusão geral:

I - O ordenamento legal da Reforma Administrativa, consubstanciado no Decreto-lei número 200/67, estabelece o princípio básico do controle dos entes administrativos através dos sistemas de atividades auxiliares, cada um exercendo-se no respectivo campo de especialização.

II - A par desses sistemas de controle, os organismos responsáveis por determinada programação conservam a autoridade normativa e exercem o controle e fiscalização de sua competência específica sobre a execução local, para efeito de liberação dos respectivos recursos, em geral condicionada ao cumprimento das diferentes etapas do cronograma pertinente (Dec.-lei n. $200 / 67$, art. $10, \S 7 .^{\circ}$ ).

III - Os controles a cargo dos sistemas de atividades auxiliares acham-se institucionalizados em torno do princípio da supervisão ministerial, que se converte, assim, em fulcro de toda a estrutura do controle interno da Administração Federal.

IV - O exercício de um desses controles não exclui o de outro, ainda que sobre o mesmo objeto, mas um e outro podem exercitar-se, simultaneamente, sejam os dos sistemas de atividades auxiliares, entre si, sejam estes em relação aos dos órgãos responsáveis por programas específicos, de vez que incidem sobre aspectos distintos da atividade administrativa.

$V$ - Os fundos especiais distribuídos aos Territórios Federais e por estes aplicados estão sujeitos, a um só tempo, à 
fiscalização dos entes personalizados da Administração Federal responsáveis pela respectiva programação e bem assim ao controle dos órgãos próprios dos sistemas de atividades auxiliares.

VI - A Inspetoria-Geral de Finanças do Ministério do Interior, como órgão setorial do Sistema de Administração Financeira, Contabilidade e Auditoria, cabe expedir o certificado de auditoria relativo às contas dos fundos especiais aplicados pelos Territórios Federais.

VII - As sociedades de economia mista constituídas nos Territórios Federais, mediante a participação destes no respectivo capital, estão abrangidas pelas disposições do art. 39 , parágrafo único, e, conseqüentemente, obrigadas ao cumprimento das exigências estatuídas nos artigos 43 e 45 , todos do DeCreto-lei n. $147 / 67$, devendo fazê-lo por intermédio da InspetoriaGeral de Finanças do Ministério do Interior, em virtude de estarem compreendidas na órbita de jurisdição administrativa dessa Secretaria de Estado. 


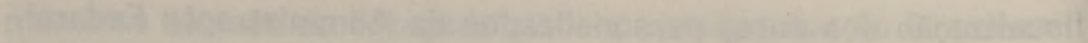
and

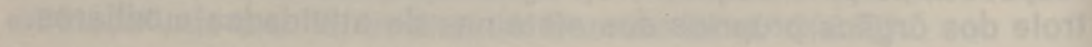

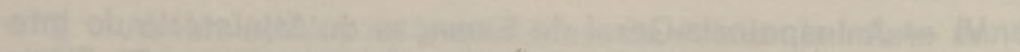

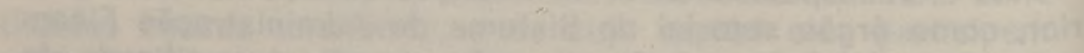

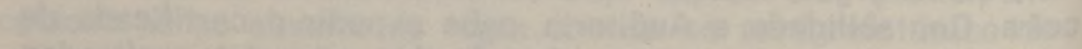

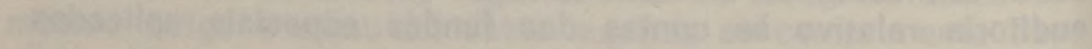

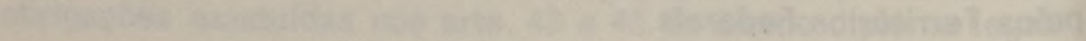

Than

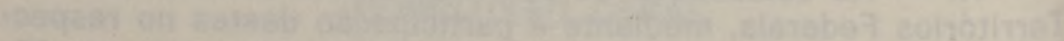

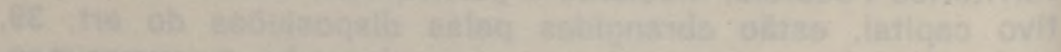

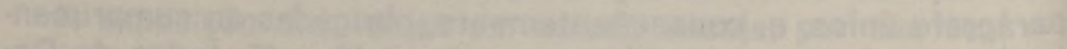

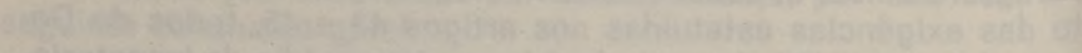

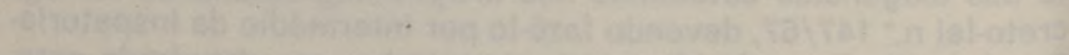

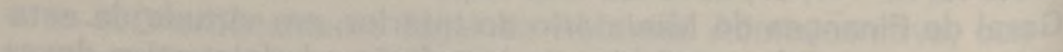

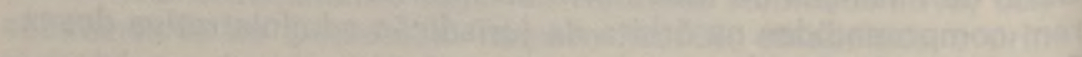

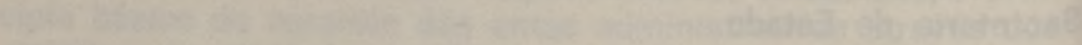
-

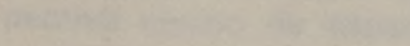

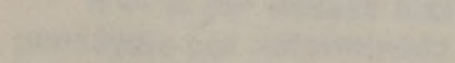
$\sin (x+2 x=$ 4.

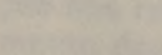

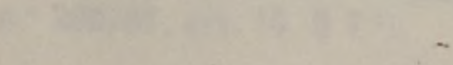

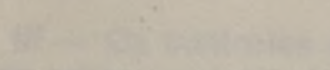

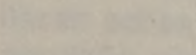
-

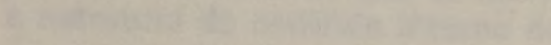

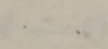

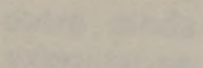

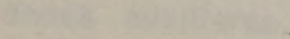

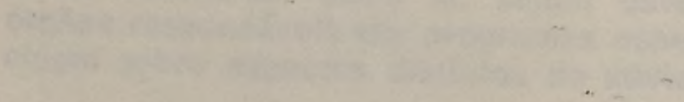

